\title{
Experimental Study on the Utilization of Borosilicate Glass Powder in Concrete
}

\author{
J Ramprashath ${ }^{1}$, N Chellakavitha ${ }^{2}$ \\ ${ }^{1}$ PG Student Department of Civil Engineering, Mepco Schlenk Engineering College, Sivakasi, Tamil Nadu, India - 626005 \\ ${ }^{2}$ Project Guide, Department of Civil Engineering, Mepco Schlenk Engineering College, Sivakasi, Tamil Nadu, India - 626005
}

\begin{abstract}
Glass from a light bulb is a waste product that cannot be utilized in a traditional way. This study looks into the possibilities of using lamp borosilicate glass powder as a cement replacing admixture in conventional concrete. Compressive Strength of the Concrete after partly replacing cement with Borosilicate Glass Powder for various percent such as 5\%, 10\%, 15\%, 20\% was tested and the optimum percentage of replacement was found to be $20 \%$. Moreover the water absorption capacity of both $R 20 \%$ and $C C$ was tested. Finely grounded Borosilicate Glass Powder of particle Size 4 Micrometer shows good performance and properties towards partial replacement of cement in Concrete.
\end{abstract}

Keywords: Waste, borosilicate glass, concrete, strength, Concrete Durability

\section{Introduction}

Concrete is an economical, versatile and highly successful construction material used to build structures. Cement is the main ingredient for concrete. By replacing cement with the waste borosilicate glass powder, it is possible to reduce the cement content there by beneficial to the environment and it is also cost effective. The experimental results indicate that replacement of cement by rough glass powder decreases the compressive strength. Fine glass particles make it possible to replace up to $20 \%$ of cement without the loss in strength characteristics [1]. Fine glass] powder offers along-term hardening effect. The best compressive strength results were achieved by using the glass that was additionally ground for 60 minutes [2]. Glass dust obtained from filters shows a less significant effect [3]. In addition to compressive strength, Water Absorption capacity of R 25\% and CC are also tested.

The main objectives of the work are as follows:

- To determine the Water absorption of Concrete cubes.

- To determine the Compressive Strength of cubes

\section{Materials}

\section{Cement}

Cement used in this investigation was 53 Grade Ordinary Portland cement confirming to IS: 12269 [18]. The specific gravity of cement was 3.15 and having initial and final setting time of $45 \mathrm{~min}$ and $560 \mathrm{~min}$ respectively.

\section{Fine Aggregate}

The fine aggregate was conforming to Zone-II according to IS: 383 [14]. The fine aggregate used was obtained from a nearby river source. The specific gravity was 2.67 , while the bulk density of sand was $1.43 \mathrm{gram} / \mathrm{c}$.c.

\section{Coarse Aggregate}

Crushed granite was used as coarse aggregate. The coarse aggregate was obtained from a local crushing unit having $20 \mathrm{~mm}$ nominal size, well graded aggregate according to IS: 383 [14]. The specific gravity was 2.83 , while the bulk density was 1.52 gram/c.c.

\section{Borosilicate Glass Powder}

Borosilicate Glass Powder of particle size 4.0 micrometer was used to replace cement. The glass powder was obtained from ball mill after additional finely grinding for more than 60 minutes. The Specific gravity was 2.2216 and having initial and final setting time of $100 \mathrm{~min}$ and $260 \mathrm{~min}$.

\section{Casting, Curing and Testing}

The concrete mix of M25 grade was prepared in a laboratory mixer with the capacity of $120 \mathrm{~kg}$. For each group, total of 6 samples of cube specimens with the dimension of $150 \mathrm{~mm}$ were prepared, of which 3 are conventional and the other 3 samples with borosilicate glass powder replacements. The specimens were kept in laboratory conditions for $24 \mathrm{~h}$ until demoulding and kept for curing.

\section{Tests Conducted}

\section{Compressive Strength}

The cube specimens were tested on compression testing machine of capacity 200 Tonnes. The bearing surface of the machine was wiped off clean and any loose sand or other material removed from the surface of the specimen the load applied was increased continuously at a constant rate until the resistance of the specimen to the increasing load breaks down and no longer can be sustained. The maximum load applied on the specimen was recorded. The compressive strength results for specimens at 28days, 56days and 90days were tabulated and compared

\section{Water Absorption}

Water absorption test was done as per ASTM C140-11a. The test specimens was immersed in water at a temperature of 60 to $80^{\circ} \mathrm{F}\left(15.6\right.$ to $\left.26.7^{\circ} \mathrm{C}\right)$ for 24 to $28 \mathrm{~h}$ such that the top surfaces of the specimens are no less than 6 in. (152 $\mathrm{mm}$ ) below the surface of the water. Specimens were separated from each other and from the bottom of the immersion tank by at least $1 / 8$ in. $(3.1 \mathrm{~mm})$. The cube was removed from the water and allowed to drain for 60 to $65 \mathrm{~s}$ by placing them on a $3 / 8$-in. $(9.5-\mathrm{mm})$ or coarser wire mesh, visible surface water was removed with a damp cloth; weighed and recorded as Ws (saturated weight). Specimens 


\section{International Journal of Science and Research (IJSR) \\ ISSN (Online): 2319-7064}

Index Copernicus Value (2013): 6.14 | Impact Factor (2015): 6.391

were dried in a ventilated oven at 212 to $239^{\circ} \mathrm{F}$ (100 to $115^{\circ} \mathrm{C}$ ) for not less than $24 \mathrm{~h}$ and dried specimens weight was noted as $\mathrm{Wd}$ (oven-dry weight).

The percentage of absorption $=\frac{W s-W d}{W d} \times 100 \%$

Where Ws = saturated weight of specimen $(\mathrm{kg})$, and $\mathrm{Wd}=$ oven-dry weight of specimen $(\mathrm{kg})$.

\section{Results and Discussion}

\section{Compressive Strength}

Fig. 2 and Table-1 shows the details of Compressive Strength of conventional concrete with and without Borosilicate Glass Powder Replacements. There is no much deviation in compressive strength. About 20\% of borosilicate glass powder replacement shows optimum results. Beyond 20\% replacement, Compressive Strength starts decreasing.

Table 1: Compressive Strength of Cubes after 28 days of Curing

\begin{tabular}{|c|c|c|c|c|c|}
\hline $\begin{array}{c}28 \text { days Comp. } \\
\text { Strength }\end{array}$ & $\begin{array}{c}\text { Conventional } \\
\text { (Mpa) }\end{array}$ & $\begin{array}{c}\text { R 5 \% } \\
\text { (Mpa) }\end{array}$ & $\begin{array}{c}\text { R 10 \% } \\
\text { (Mpa) }\end{array}$ & $\begin{array}{c}\text { R 15\% } \\
\text { (Mpa) }\end{array}$ & $\begin{array}{c}\text { R 20 \% } \\
\text { (Mpa) }\end{array}$ \\
\hline Trial 1 & 32 & 31 & 30 & 30 & 30 \\
\hline Trial 2 & 31 & 30.25 & 32 & 31 & 29 \\
\hline Trial 3 & 30 & 31.8 & 31 & 30 & 30 \\
\hline Average & 31 & 31.01 & 31 & 30.33 & 30 \\
\hline
\end{tabular}

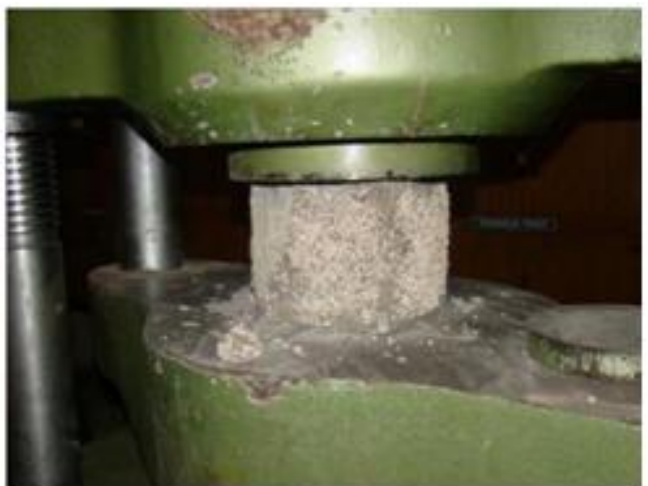

Figure 2: Cubes tested for its compressive strength in UTM

\section{Water Absorption}

Table- 8 shows the details of the Water Absorption capacity of $\mathrm{CC}$ and $\mathrm{R} 20 \%$. The rate of Water Absorption increases on addition of Borosilicate Glass Powder but they are very much less than that of the maximum permissible limit of $12 \%$.

Table 8: Comparison between the percentages of Water

\begin{tabular}{|c|c|c|c|c|}
\multicolumn{4}{c|}{ Absorption of CC and R 20 \% Cubes } \\
\hline \multirow{2}{*}{ CC } & $\begin{array}{c}\text { Saturated } \\
\text { Weight (g) }\end{array}$ & $\begin{array}{c}\text { Dry } \\
\text { Weight (g) }\end{array}$ & $\begin{array}{c}\text { \% of Water } \\
\text { absorption }\end{array}$ & $\begin{array}{c}\text { Average \% of } \\
\text { Water } \\
\text { Absorption }\end{array}$ \\
\cline { 2 - 4 } & 8.915 & 8.815 & 1.134 & \multirow{2}{*}{$0.97 \%$} \\
\cline { 2 - 4 } & 8.8 & 8.715 & 0.975 & \multirow{2}{*}{} \\
\cline { 2 - 4 } R $20 \%$ & 8.835 & 8.765 & 0.799 & \multirow{2}{*}{$2.54 \%$} \\
\cline { 2 - 4 } & 8.915 & 8.69 & 2.589 & \\
\cline { 2 - 4 } & 8.955 & 8.79 & 1.877 & \multicolumn{1}{|c}{} \\
\cline { 2 - 4 } & 8.975 & 8.7 & 3.161 & \\
\hline
\end{tabular}

\section{Conclusion}

Based on the experimental investigations, the following conclusions have been drawn:

- The Compressive strength doesn't vary much up to $20 \%$ replacement of cement with Borosilicate Glass Powder.

- Beyond 20\% replacement, compressive strength starts decreasing.

- The water Absorption capacity of R $20 \%$ is more when compared to $\mathrm{CC}$ but both are less than the maximum limit of $12 \%$.

\section{References}

[1] Aleksandrs Korjakins, Genadij Shakhmenko and Girts Bumanis, "Utilization of Borosilicate Glass Waste as a Micro-Filler for Concrete" in theJournal of Civil Engineering and Architecture, ISSN 1934-7359, USA, July 2012, Volume 6, No. 6 (Serial No. 56), pp. 876-883

[2] Nathan Schwarz, Hiue cam, Narayanan Neithalath, "Influence of fine glass powder on durability characteristics of concrete and its comparision to fly ash" in Science Direct, Vol. 30, Issue 6, July 2008.

[3] Nathan Schwarz, Hiue cam, Narayanan Neithalath, "Influence of fine glass powder on durability characteristics of concrete and its comparision to fly ash" in Science Direct, Vol. 30, Issue 6, July 2008. 